\title{
Effect of age on the sildenafil impact on the histological and ultra-structure of the liver in male albino rat
}

Hagar A. Hashish

Correspondence: nada_2612@yahoo.com

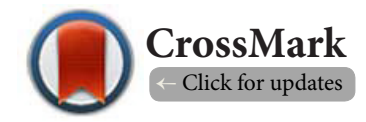

Department of Human Anatomy, Faculty of Medicine, Mansoura University, Egypt.

\begin{abstract}
Background: Sildenafil is one of PDE-5(phospho-diestrase enzyme) inhibitors. It is used as an antihypertensive drug. Sildenafil is mainly metabolized in the liver, and there are cautions regarding the dose when prescribing sildenafil to children, and patients with hepatic impairment.

Materials and method: 24 male albino rats (150-350gm weight) were used. Animals were divided into four groups (6 rats each). The rats of treated groups $(2,3$ and 4$)$ received $(1.43 \mathrm{mg} / \mathrm{kg}$ body weight) of sildenafil citrate. The Control group received equal volume of distilled water daily during the period of the experiment. At the end of treatment after 30 days, liver samples were collected, processed and stained with (Haematoxylin \& Eosin stain) for histological examination. For, ultrastructure studies, specimens were cut into small pieces, processed and ultra thin sections were cut, mounted on the copper grids. Sections were examined by JEOL100SX transmission electron microscope connected to a digital camera.
\end{abstract}

$\underline{\text { Result: }}$ The pre-pubertal rats showed congested central vein and hepatic artery. Areas of inter-cellular vacuolization were observed. Adult rats showed congested central vein, hepatic artery and portal veins with severe inflammatory cell infiltration. Most of hepatocytes exhibited vacuolated cytoplasm and pyknotic nuclei. The senile rats showed congestion in both portal and central veins and increased number of von-kupffer cells. Areas of hemorrhage and necrosis were observed between hepatocytes. Most hepatocytes were degenerated with reduction of number.

Conclusion: Sildenafil Citrate drug may cause serious effect on the liver, this effect becomes worse with advance in age.

Keywords: Liver, sildenafil citrate, von-kupher, hepatocyte

\section{Introduction}

Sildenafil is one of PDE-5(phospho-diestrase enzyme) inhibitors. It is used as an antihypertensive drug. Sildenafil is a selective inhibitor of PDE-5, the enzyme which metabolizes cGMP in the corpus cavernosum of the penis. CGMP is a mediator of smooth muscle relaxation and vasodilatation of blood vessels in the penis. By this action, sildenafil can prolong the duration of penile erection [1].

PDE-5 enzyme is also located in the pulmonary artery smooth muscle [2] Sildenafil increases the potency of cGMP and nitric oxide which is potent short-acting pulmonary vasodilator. Studies on rat neonates with hypoxia,treated by sildenafil,revealed increased pulmonary cGMP levels, reducedinflammatory response and fibrin deposition [3].

Sildenafil is mainly metabolized in the liver, and there are cautions regarding the dose when prescribing sildenafil to children, and patients with hepatic impairment [4].

The hepatic structural changes induced by sildenafil administration are not yet well identified. The present paper aims to clarify the possible structural alterations in the hepatic tissues following experimental sildenafil administration with respect to age.

\section{Materials and methods \\ Experimental animals}

24 male albino rats (150-350gm weight) were used. The use of experimental animals was prospectively approved by the Ethical Committee, Mansoura University, Faculty of Medicine. The rats were housed in animal care center of Mansoura Faculty of Medicine. The rats were provided with fresh food and water 
daily and inspected for any possible signs of inflammation or infection.

\section{Experimental design}

Animals were divided into four groups (6 rats each):

First group: control adult rats.

Second group: prepubertal treated rats.

Third group: adulttreated rats.

Fourth group: senile treated rats.

\section{Sildenafil citrate administration}

The rats of treated groups (2, 3 and 4$)$ received $(1.43 \mathrm{mg} / \mathrm{kg}$ body weight) of sildenafil citrate, after being dissolved in distilled water, every day for 30 days, through oro-gastric feeding tube. The giving doses were similar to the recommended human oral doses (100 mg) [5]. The Control group received equal volume of distilled water daily during the period of the experiment through oro-gastric feeding tube. Sildenafil citrate was supplied from Pfizer Inc. (Egypt), was stored at $2-4^{\circ} \mathrm{C}$ and protected from sunlight.

\section{Histological analysis}

At the end of treatment after 30 days, rats of each group were anaesthetized with diethyl ether, vertical ventral midline incision was made in the abdominal wall in order to get the liver samples. The samples were preserved in $10 \%$ formalin, for 24 hours, processed for paraffin sections, were stained with (Haematoxylin \& Eosin stain) for microscopical examination.

\section{Tissue preparation for ultrastructural study}

The specimens were cut into small pieces $1 \mathrm{~mm} 3$. They were immediately fixed in cold $3.5 \%$ glutaraldehyde in $0.1 \mathrm{M}$ phosphate buffer (PH: 7.2), then fixed with $1 \%$ osmium tetraoxide (OsO4), processed and embedded in epon. Semithin sections $(1 \mu \mathrm{m}$ thick) stained with toluidine blue stain and examined by the light microscope. Ultrathin sections (50-70nm thick) were cut, mounted on the copper grids. Then stained with uranyl acetate and lead citrate [6]. Sections were examined by JEOL-100SX transmission electron microscope connected to a digital camera.

\section{Quantitative analysis}

The hepatocytes were measured in a fixed field in serial sections by using Leica Quin 500 " image analyzer computer system (England). Evaluation of hepatocytes degeneration was assessed as the following: mild $0-25 \%$ of hepatocytes are degenerated, Moderate $25-50 \%$, sever $50-75 \%$ [7]. The degree of infiltration with the inflammatory cells was calculated according to the grading system: 0 , absent; I, mild; 2 , moderate; 3 sever [8].

\section{Statistical analysis}

The analysis was carried out through computer software SPSS program (statistical package for social science) version 10. The data were collected as the mean \pm SD. The significance level considered was $\mathrm{P} \leq 0.05$.

\section{Results \\ 1-Light microscopic examination of liver specimens Control rats}

Histological examination of liver section in this groups showed classical lobules with radiating and anastomosing cords of hepatocytes arising from the central vein. The cords of hepatocytes were separated by hepatic sinusoids which were lined by von-kupffer cells. The portal triad showed a clear branch of portal vein, hepatic artery and bile duct (Figures 1 and $\mathbf{5 A}$ ).

\section{Sildenafil treated rats \\ Prepubertal rats}

The liver lobular architecture was maintained in this group. The central vein and hepatic artery were congested. There were moderate inflammatory cell infiltration around the central vein. Few areas of intercellular vacuolization were observed. The bile ducts showed mild hyperplasia. Some hepatocytes exhibited pyknotic nuclei (Figures 2 and 5B).

\section{Adult rats}

The hepatic lobular architecture was preserved in this group. The central vein, hepatic artery and portal veins were congested. There was moderate inflammatory cell infiltration (lymphocytes and neutrophils) around the portal vein. Areas of intercellular vacuolization were observed in liver parenchyma. The bile ducts showed severe hyperplasia. Most hepatocytes exhibited vacuolated cytoplasm and pyknotic nuclei, with intercellular areas of hemorrhage and necrosis (Figures 3 and $\mathbf{5 C}$ ).

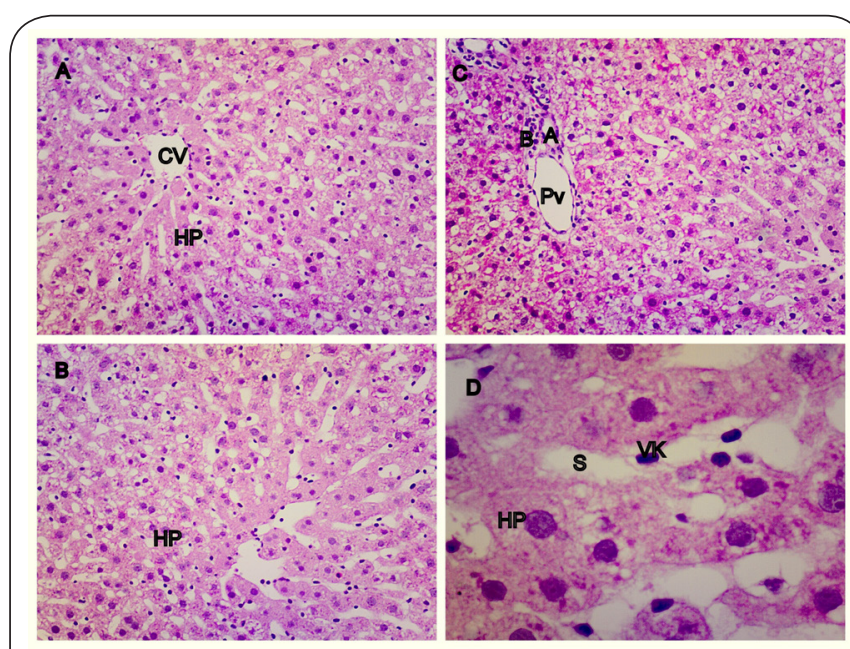

Figure 1. A photomicrograph of section in liver of control rat. $\mathbf{A} \& \mathbf{B}$. Classical lobule with radiating and anastomosing cords of hepatocytes (HP) arising from the central vein (CV). C. The portal triad shows a clear branch of portal vein $(\mathrm{Pv})$, hepatic artery (A) and bile duct (B). D. The cords of hepatocytes are separated by hepatic sinusoids (S), which are lined by von-kupffer cells (VK) (Hx\&E; A,B,C X100 D X400). 


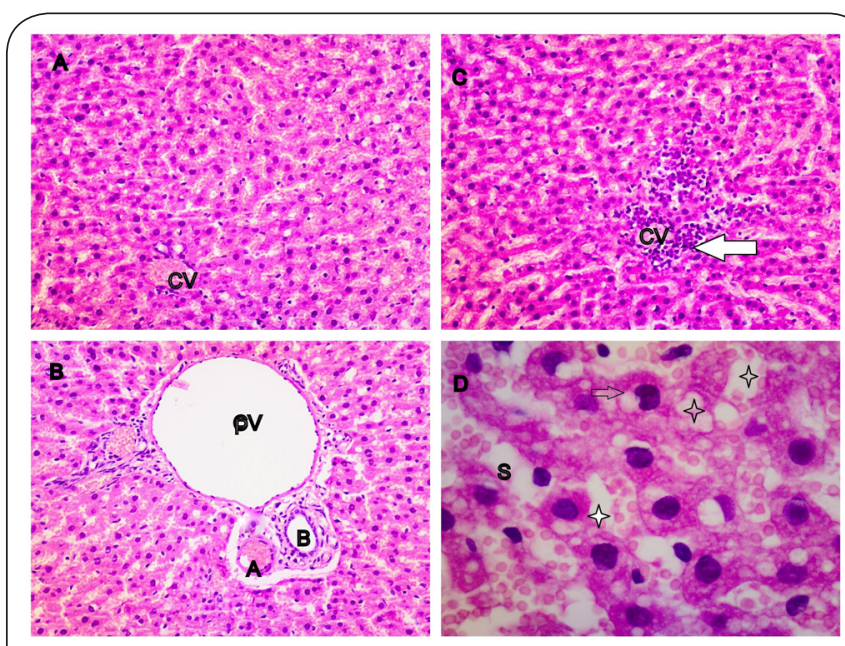

Figure 2. A. photomicrograph of section in liver of prepubertal rats $\mathbf{A}$. The liver lobular architecture is intact in this group. The central vein $(\mathrm{CV})$ is congested. $\mathbf{B}$. The bile duct shows mild hyperplesia (B), congested hepatic artery is noticed (A). C. Moderate inflammatory cell infiltration around the central vein (arrow). D. Areas of intercellular vacuolization are observed ${ }^{*}$ ). Some hepatocytes exhibits pyknotic nuclei (arrow). Hx\&E (A,B,C X100 D x400).

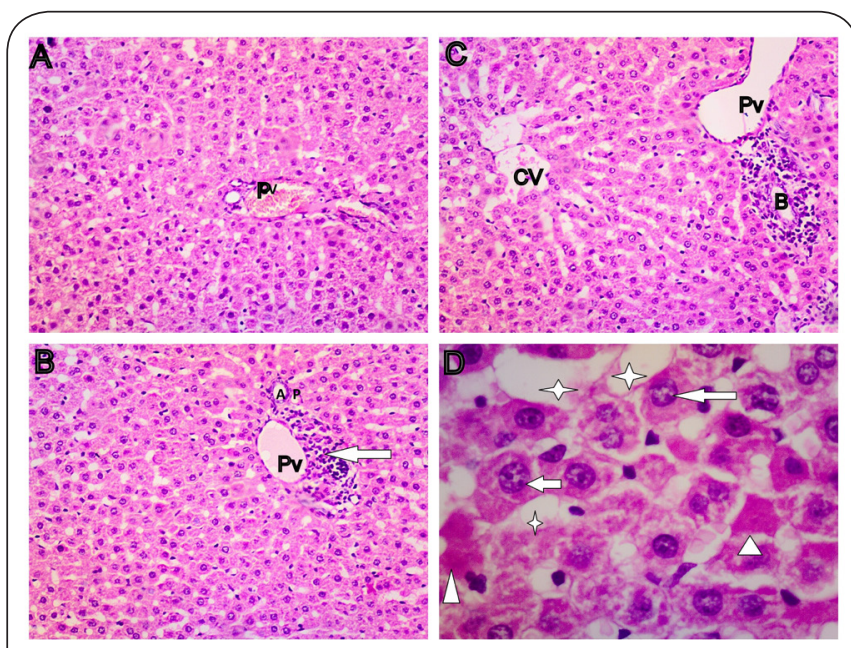

Figure 3. A. Photomicrograph of section in liver of adult rats $\mathbf{A} \& \mathbf{B}$. The portal vein (Pv) is congested, with inflammatory cell infiltration around the portal vein (arrow). C. The bile duct shows severe hyperplasia (B) and central vein is congested (CV). D. Areas of intercellular vacuolization are observed in liver parenchyma $\left({ }^{*}\right)$. Most of hepatocytes shows vacuolated cytoplasm and pyknotic nuclei (arrows), with intercellular areas of hemorrhage and necrosis (arrow head). Hx\&E $(\mathrm{A}, \mathrm{B}, \mathrm{C} \times 100) \mathrm{D} \times 400$.

\section{Senile rats}

This group showed marked congestion in both portal and central veins and increased number of von-kupffer cells. Areas of hemorrhage and necrosis were observed between hepatocytes and around central vein. Most hepatocytes degenerated with reduction of number. Focal intercellular vacuolization was observed in liver parenchyma (Figures 4 and 5D).

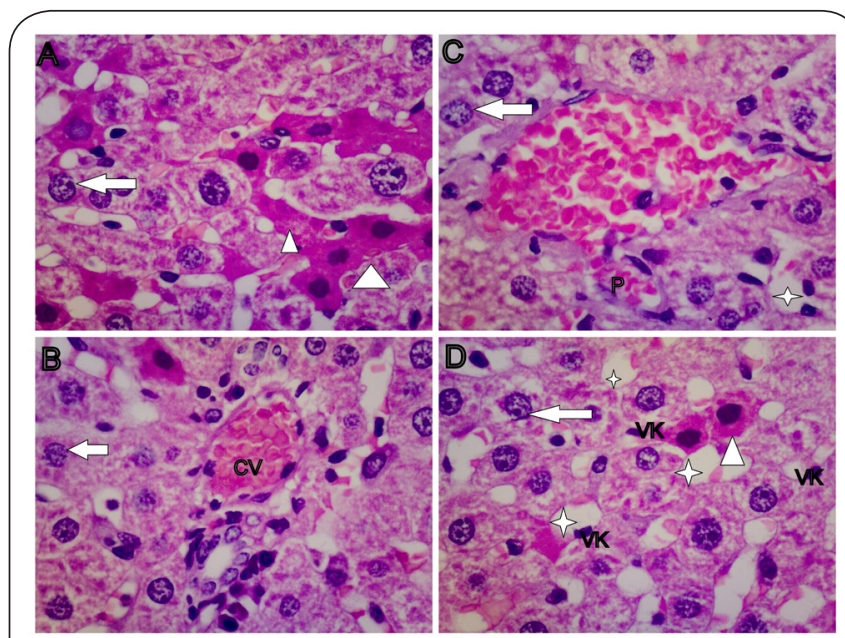

Figure 4. A. photomicrograph of section in liver of senile rats $\mathbf{A} \& \mathbf{B} \& \mathbf{C}$ marked congestion in both portal $(\mathrm{P})$ and central veins $(\mathrm{CV})$, areas of hemorrhage and necrosis (arrow heads). Most hepatocytes are degenerated with reduction of number(arrows). D. Intercellular vacuolization $\left(^{*}\right)$ in liver parenchyma with increased number of von-kupffer cells (VK) and areas of hemorrhage (arrow head). (Hx\&E x400).

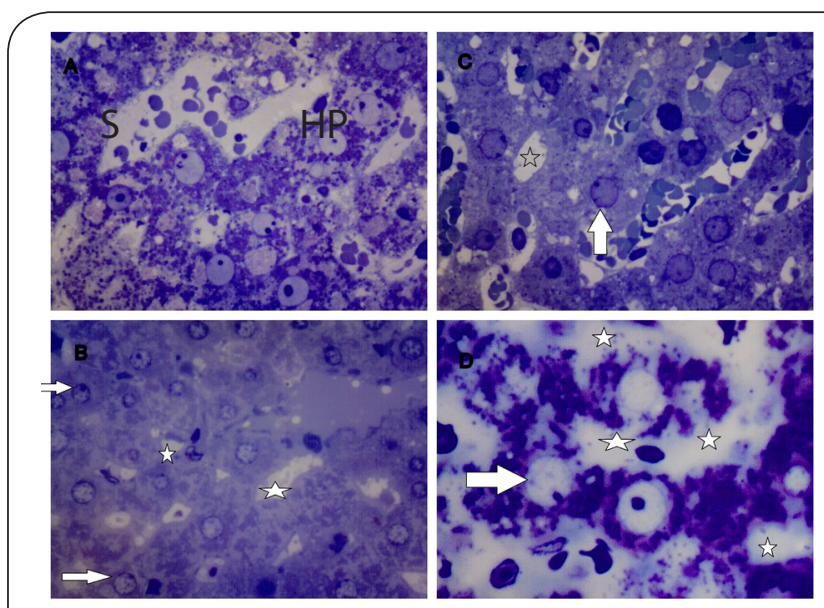

Figure 5. A. Photomicrograph of section in liver of control, treated prebubertal, adult and senile rats $\mathbf{A}$. normal hepatocytes (HP) and liver sinusoids (S). B\&C\&D. degenerated cells (arrows)with intercellular vacuolization in treated groups $\left(^{* *}\right)$. (Toluidine blue X 400).

\section{Transmission electron microscopic examination of the liver specimens Control rats}

Transmission electron micrograph sections in the liver of control rats showed hepatocytes with spherical nucleus, mitochondria, glycogen granules, rough endoplasmic reticulum. Von-Kupher cells and blood cell were seen (Figure 6). 

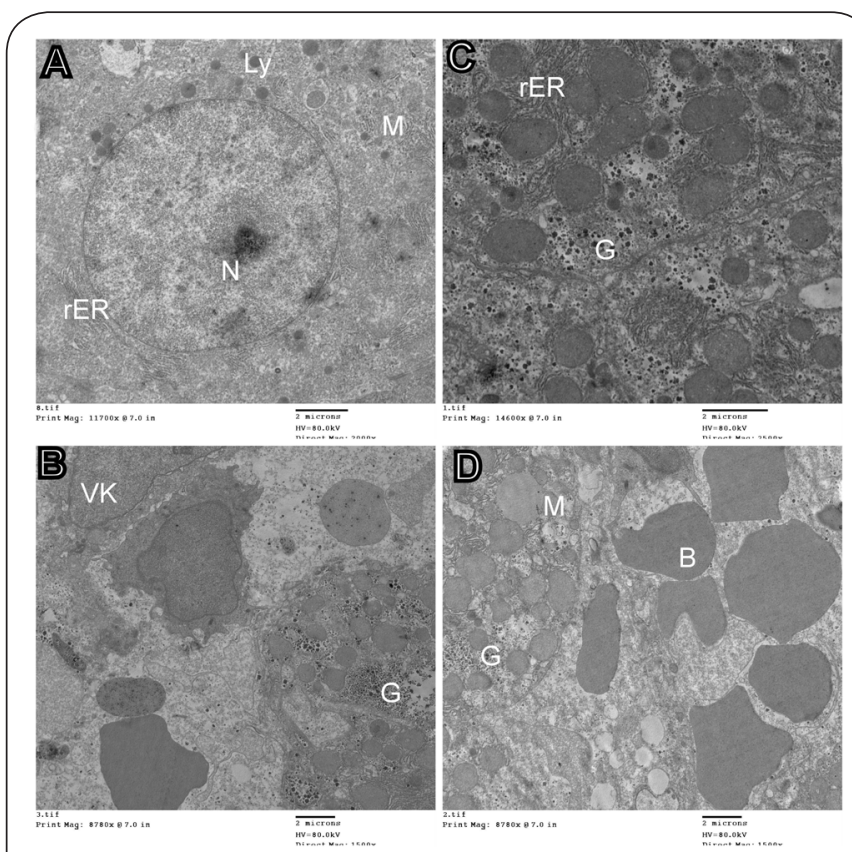

Figure 6. Transmission electron micrograph of the liver of control rats. A., C. normal hepatocytes with spherical nucleus $(\mathrm{N})$, mitochondria $(\mathrm{M})$, rough endoplasmic reticulum (rER), glycogen granules (G). B,D. Von-Kupher (VK) blood cells (B) are obvious. Scale bar $=2$ microns.

\section{Sildenafil treated rats In prepubertal rat}

In this group hepatocytes appeared with spherical nucleus and dispersed chromatin, mitochondria, dilated rough endoplasmic reticulum, lysosomes and phagosomes; Von-Kupher cells was identified (Figure 7).

\section{Adult rat}

Transmission electron micrograph of the liver of adult treated rats showed some hepatocytes, with two spherical nuclei, dispersed chromatin and irregular nuclear membrane, swollen mitochondria, dilated rough endoplasmic reticulum, lysosomes and phagosomes. Cytoplasmic vacuoles were noticed (Figure 8).

\section{Senile rats}

Transmission electron micrograph of the liver of senile treated rats showed hepatocytes, with irregular indented nucleus with dispersed chromatin, irregular nuclear membrane, swollen mitochondria with unclear cristae, dilated rough endoplasmic reticulum, lysosomes and phagosomes. Sever inter cellular vacuolization was noticed (Figure 9).

\section{Morphometric results and statistical analysis}

In comparison with the control group, the area \% of degenerated hepatocytes showed a significant increase in the treated groups especially the senile rats (Graph 1 ).

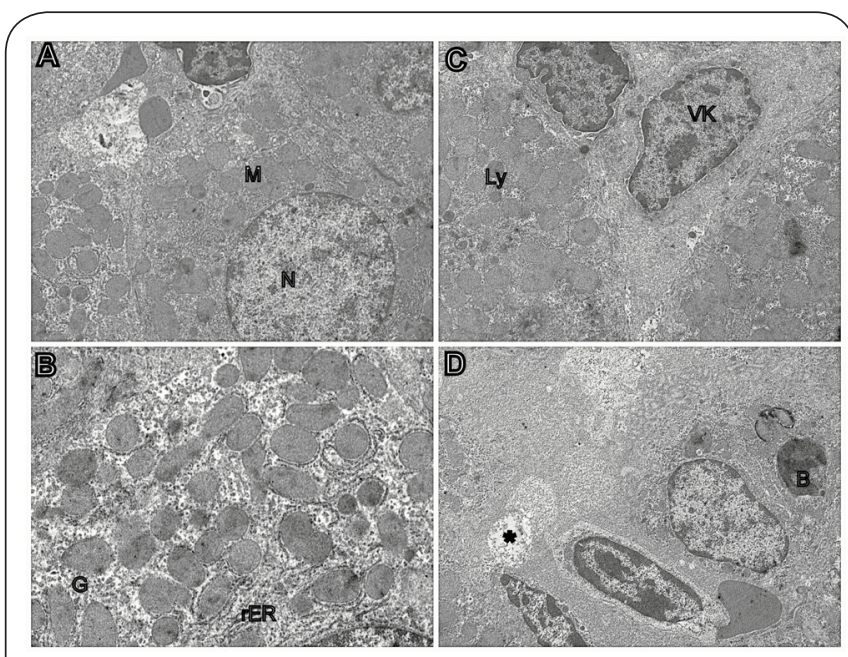

Figure 7. Transmission electron micrograph of the liver of treated prepubertalgroup rats. A,B. hepatocytes with spherical nucleus $(\mathrm{N})$, electron dense mitochondria $(\mathrm{M})$, glycogen granules $(\mathrm{G})$, dilated rough endoplasmic reticulum (rER). C,D.lysosomes and phagosomes (Ly),Von-Kupher (VK) and blood cells(B) are obvious. Intercellular vacuolation can be observed $\left({ }^{*}\right)$. Scale bar $=2$ microns.
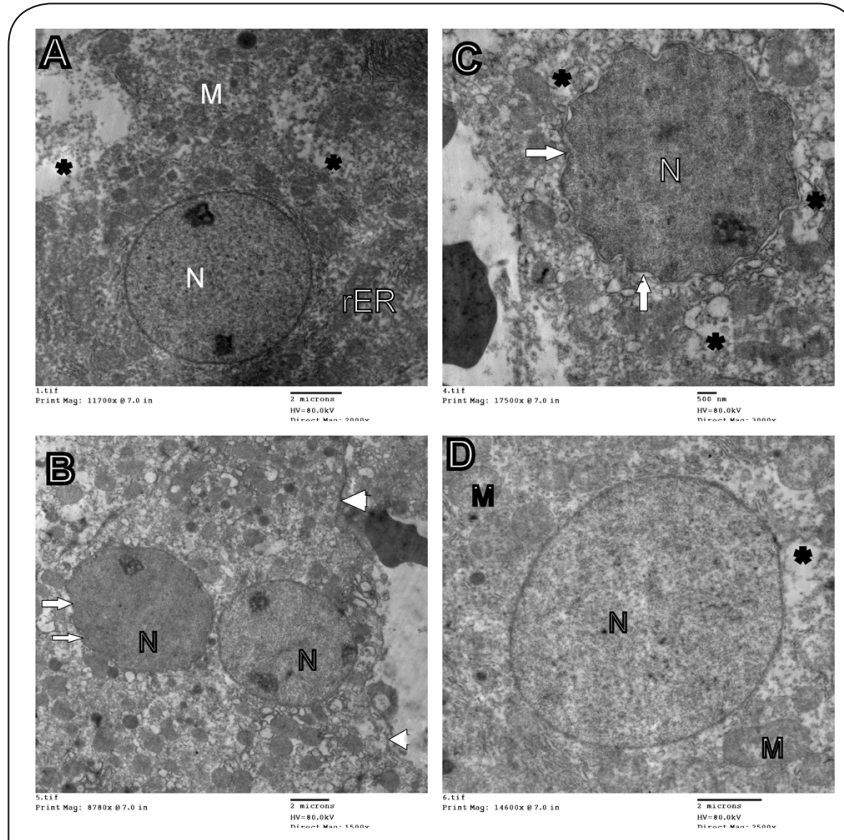

Figure 8. Transmission electron micrograph of the liver of treated adult rat. A. hepatocytes appears with spherical nucleus $(\mathrm{N})$ and dispersed chromatin, mitochondria (M), dilated rough endoplasmic reticulum (rER) and areas of cytoplasmic vacuolization $\left.{ }^{*}\right)$. B. binucleated hepatocytes with irregular nuclear membrane (arrow) and interrupted cell membrane (arrow head). C,D. The nucleus appear with irregular nuclear membrane (arrow), dilated mitochondria $(M)$ and areas of cytoplasmic vacuolization ${ }^{*}$ ) (Scale bar $\mathrm{A}, \mathrm{B}, \mathrm{D}=2$ microns $\mathrm{C}=500 \mathrm{~nm})$. 

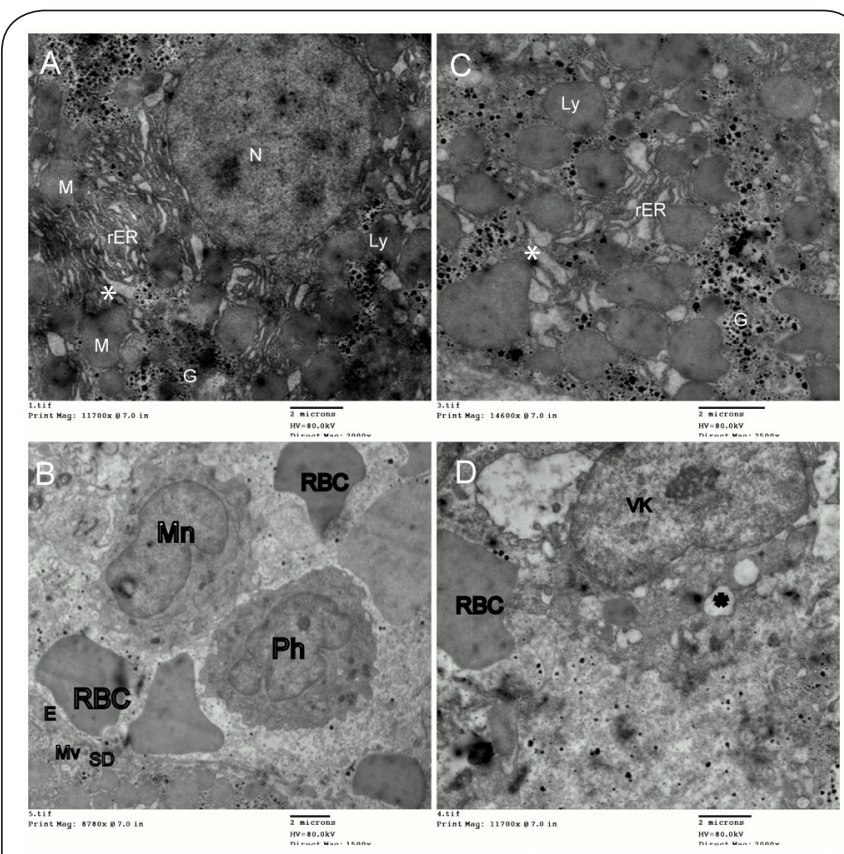

Figure 9. Transmission electron micrograph of the liver of treated senile rat. A.,C. The nucleus with dispersed chromatin and irregular nuclear membrane, swollen mitochondria (M), dilated rough endoplasmic reticulum (rER) and cytoplasmic vacuoles $\left({ }^{*}\right)$. B. Hepatic sinusoid contains red blood cells (RBCS), Monocyte (Mn), phagocytic cell (Ph). Space of disse (SD) lies between endothelium of hepatic sinusoid (E) and hepatocyte, microvilli of hepatocyte can be detected (Mv) D. Von-Kupher (VK) and red blood cells (RBCs) are obvious, areas of cytoplasmic vacuolization $\left(^{*}\right)$ Scale bar $=2$ microns.

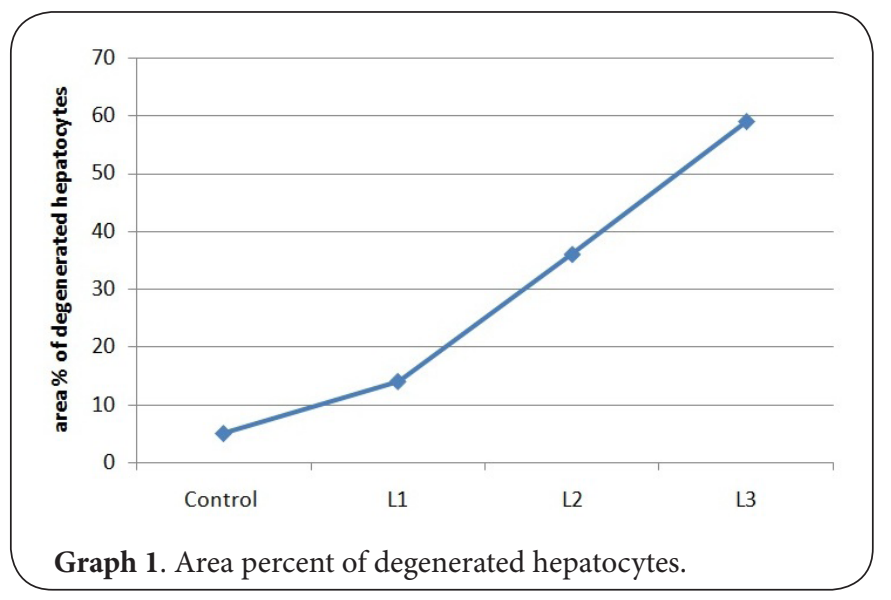

\section{Discussion}

As liver has the sole role in detoxification and excretion of drugs, administration of injurious materials, it is the first organ to be affected through the portal circulation [9]. Although several studies have demonstrated some side-effects of the sildenafil drug on liver, the present study is the first one that reveals morphological changes both at cellular and ultra-structural levels with respect to the age of the rat.

Sildenafil is mainly metabolized in the liver, and there are major considerations when prescribing sildenafil dose to neonates, children, and patients with hepatic impairment. In the first days of neonatal life, the clearance of sildenafil is about one-third of that seen in adults with increased half-life of 48-56 hours. This could be explained by immaturity of the cytochrome P450 system, which becomes mature in the first week of life [10].

The present study revealed that liver lobular architecture was intact in prepubertal treated group. The central vein, hepatic artery were congested. There were moderate inflammatory cell infiltration (lymphocytes and neutrophils) around the central vein. Only a few areas of intercellular vacuolization were observed. The bile ducts showed mild hyperplesia. Some hepatocytes exhibited pyknotic nuclei. Similar findings reported that exposure of prepubertal rats to Ribnacin drug induced hepatocyte necrosis and mononuclear cell infiltration in the portal tract [11]. It was documented that the hepatocellular injury due to any factor is mediated through free-radicle from lipid peroxidation [12].

The current study revealed that ingestion of sildenafil in adult rats caused congestion of the central vein, hepatic artery and portal veins. There was moderate inflammatory cell infiltration (lymphocytes and neutrophils) around the portal vein. Areas of intercellular vacuolization were observed in liver parenchyma. The bile ducts showed severe hyperplasia. Most of hepatocytes showed vacuolated cytoplasm with pyknotic nuclei, with intercellular areas of hemorrhage and necrosis. Transmission electron micrograph of the liver of adult treated rats showed hepatocytes, with dispersed chromatin and irregular nuclear membrane, swollen mitochondria, rough endoplasmic reticulum, lysosomes and phagosomes. Cytoplasmic vacuoles were noticed.

Similar results have been reported after injection of sildenafil ( $1 \mu \mathrm{g} / \mathrm{g}$ body wt.) in adult rats for 15 days, in the form of central vein congestion and cytoplasmic vacuolization [13]. It was documented that cytoplasmic vacuolization is one of the primary responses to any cell injury. It occurs as a result of increased permeability of cell membranes leading to increase in the intracellular water content [14].

Also, injection of $9 \mathrm{mg} / \mathrm{kg}$ of sildenafil in adult rabbit induced hepatocytes nuclear changes. This change may be due to cell injury [15]. karyolysis was observed in sildenafil overdoses. Nuclear changes caused by chromatin condensation while karyolysis resulted from chromatin matter dissolution of a necrotic cells [16]. The presence of inflammatory cells in the liver after sildenafil exposure may indicate an effect of this drug on the antioxidant defense which may cause generation of reactive oxygen species and inflammatory response [17]. In addition, sildenafil can cause lysosomal enzymes leakage and cytoplasmic degeneration. The degeneration may be due tocell membrane disturbance and massive influx of water and sodium ions [18]. 
This study revealed that the treated senile rats showed marked congestion in both portal and central veins, increased number of von-kupffer cells. Areas of hemorrhage and necrosis were observed between hepatocytes and around central vein. Most hepatocytes were degenerated with reduction in number. Intercellular vacuolization were observed in between liver cells.

In human, a case of sildenafil-induced liver disorder was reported in 49 year-old male after 4 weeks of drug initiation in dose of $50 \mathrm{mg} /$ day. He presented with pain in the right hypochondrium, hepatomegaly and elevated liver enzymes. All other investigations were normal including anti bodies to hepatitis $B$, hepatitis and hepatitis $C$. Liver enzymes returned to normal values after sildenafil withdrawal in 20 days [19].

The sever hepatic changes in senile rats may be explained according to the fact that there is a reduction in drugs clearance with age especially those undergo transformation by liver microsomal mono-oxygenase [20]. In 1968, Kato and Tanaka were the first to report a significant age-related reduction in the activities of the microsomal mono-oxygenase hepatic enzyme in male rats in vitro [21].

Studies in humans showed that aging is associated with reduction in hepatic drug metabolism. Cytochrome P450 in human decreases $30 \%$ after the age of 70 years. Reduced drug metabolism may be also due to reduction of liver voume and the blood flow [22]. The apoptotic potential of the liver decrease with advance of age. So, the injured and pre-neo plastic cells may increase in liver with advanced age. This may explain the brown atrophy and hepatocellular neoplasms with old ages [23].

Also, aging is associated with increase of gene expression associated with fibrosis, stress of the cell and inflammation. This gene is normally associated with activation of macrophages [24]. Activated macrophages and inflammatory cells are included in some liver diseases like cirrhosis, hepatitis, endotoxin-induced liver lesion [25].

This study provides evidence that Sildenafil Citrate drug may cause seroius effect on the liver, which becomes worse with advance in age. Further studies are needed to assess whether these morphological changes are transitory or irreversible.

\section{Competing interests}

The author declares that he has no competing interests.

\section{Acknowledgement}

The author thanks Prof. Dr. Amany M Shams professor of Anatomy and all the staff members of Anatomy and Embryology Department in Faculty of Medicine, Mansoura University, Egypt, for their co-operation and helpful comments during this work.

\section{Publication history}

EIC: Gaetano Giuseppe Magro, University of Catania, Italy. Received: 05-Nov-2016 Final Revised: 14-Dec-2016

Accepted: 19-Dec-2016 Published: 28-Dec-2016

\section{References}

1. Naylor AM. Endogenous neurotransmitters mediating penile erection. BrJ Urol. 1998; 81:424-31. | Article | PubMed
2. Humpl T, Reyes JT, Holtby H, Stephens D and Adatia I. Beneficial effect of oral sildenafil therapy on childhood pulmonary arterial hypertension: twelve-month clinical trial of a single-drug, open-label, pilot study. Circulation. 2005; 111:3274-80. | Article | PubMed

3. Reffelmann T and Kloner RA. Therapeutic potential of phosphodiesterase 5 inhibition for cardiovascular disease. Circulation. 2003; 108:239-44. | Article | PubMed

4. Koukouritaki SB, Manro JR, Marsh SA, Stevens JC, Rettie AE, McCarver DG and Hines RN. Developmental expression of human hepatic CYP2C9 and CYP2C19. J Pharmacol Exp Ther. 2004; 308:965-74. | Article | PubMed

5. Eweka $O$ and Eweka B.The effects of sildenafil citrate on the superior colliculus of adultwistar rats (Rattusnorvegicus) - a histological study. Biology and Medicine. 2010; 2:24-29.

6. Hayat M. Principles and techniques of electron microscopy, biological applications. $3^{\text {rd }}$ ed. CRC press. 1989; 24-74.

7. Gokcimen A. Melatonin decreases morphological changes in liver induced by magnetic field exposure in rats. Tip FakultesiDergisi. 2000; 7:47-52.

8. Brunt EM. Grading and staging the histopathological lesions of chronic hepatitis: the Knodell histology activity index and beyond. Hepatology. 2000; 31:241-6. | Article | PubMed

9. Katzung B G. Basic and clinical pharmacology. 3rd ed. Appleton and Lang. Connecticut USA. 1999.

10. Hill KD, Sampson MR, Li JS, Tunks RD, Schulman SR and Cohen-Wolkowiez $M$. Pharmacokinetics of intravenous sildenafil in children with palliated single ventricle heart defects: effect of elevated hepatic pressures. Cardiol Young. 2016; 26:354-62. | Article | PubMed

11. Dioka C, Orisakewi OE, Afon OJ, Agbasi AU, Akumka D, Okonkow C and lloundo N. Investigation on the haematologic and Hepatotoxic effect of Ribnacin on rat liver. J of health science. 2002; 48:393-398. | Pdf

12. Kirk HD, Berdasco NM, Breslin WJ and Hanley TR, Jr. Developmental toxicity of 1,2-dichloropropane (PDC) in rats and rabbits following oral gavage. Fundam Appl Toxicol. 1995; 28:18-26. | Article | PubMed

13. Suriyakumari KVP, Dayakumar R and Panneerselvam A. Sildenafil citrate induced histological changes in liver of albino mice. International J. of Healthcare and Biomedical Research. 2015; 3:94-98.

14. Sherlock $S$ and Dooley J. In: Diseases of the liver and billiary system. 9th ed. Blackwell Scientific Publication, Cambridge, London. 1993: 649.

15. Gerlyng P, Abyholm A, Grotmol T, Erikstein B, Huitfeldt HS, Stokke T and Seglen PO. Binucleation and polyploidization patterns in developmental and regenerative rat liver growth. Cell Prolif. 1993; 26:557-65. | Article I PubMed

16. Pandey G, Srivastava DN and Madhuri S. A standard hepatotoxic model produced by paracetamol in rat. Toxicology international. 2008; 15:6970.

17. Johar D, Roth JC, Bay GH, Walker JN, Kroczak TJ and Los M. Inflammatory response, reactive oxygen species, programmed (necrotic-like and apoptotic) cell death and cancer. Rocz Akad Med Bialymst. 2004; 49:319. | Article | PubMed

18. Del Monte U. Swelling of hepatocytes injured by oxidative stress suggests pathological changes related to macromolecular crowding. Med Hypotheses. 2005; 64:818-25. | Article | PubMed

19. Daghfous R, El Aidli S, Zaiem A, Loueslati MH and Belkahia C. Sildenafilassociated hepatotoxicity. Am J Gastroenterol. 2005; 100:1895-6. | Article I PubMed

20. Le Couteur DG and McLean AJ. The aging liver. Drug clearance and an oxygen diffusion barrier hypothesis. Clin Pharmacokinet. 1998; 34:35973. | Article | PubMed

21. Tanaka E. In vivo age-related changes in hepatic drug-oxidizing capacity in humans. J Clin Pharm Ther. 1998; 23:247-55. | Article | PubMed

22. Thompson PD, Hsieh JC, Whitfield GK, Haussler CA, Jurutka PW, Galligan MA, Tillman JB, Spindler SR and Haussler MR. Vitamin D receptor displays DNA binding and transactivation as a heterodimer with the retinoid $\mathrm{X}$ receptor, but not with the thyroid hormone receptor. J Cell Biochem. 1999; 75:462-80. | Article | PubMed 
Hagar A. Hashish, Journal of Histology \& Histopathology 2016, http://www.hoajonline.com/journals/pdf/2055-091X-3-5.pdf

23. Suh Y, Lee KA, Kim WH, Han BG, Vijg J and Park SC. Aging alters the apoptotic response to genotoxic stress. Nat Med. 2002; 8:3-4. | Article I PubMed

24. Keshav S, Chung P, Milon G and Gordon S. Lysozyme is an inducible marker of macrophage activation in murine tissues as demonstrated by in situ hybridization. J Exp Med. 1991; 174:1049-58. | Article | PubMed Abstract I PubMed FullText

25. Jaeschke H. Cellular adhesion molecules: regulation and functional significance in the pathogenesis of liver diseases. Am J Physiol. 1997; 273:G602-11. | Article | PubMed

\section{Citation:}

Hashish HA. Effect of age on the sildenafil impact on the histological and ultra-structure of the liver in male albino rat. J Histol Histopathol. 2016; 3:5.

http://dx.doi.org/10.7243/2055-091X-3-5 